\title{
Clinical expert consensus document on quantitative coronary angiography from the Japanese Association of Cardiovascular Intervention and Therapeutics
}

\author{
Nobuaki Suzuki ${ }^{1}$ Taku Asano ${ }^{2}$. Gaku Nakazawa ${ }^{3}$ Jiro Aoki ${ }^{4} \cdot$ Kengo Tanabe $^{4} \cdot$ Kiyoshi Hibi $^{5} \cdot$ Yuji Ikari $^{6}$. \\ Ken Kozuma ${ }^{7}$
}

Received: 19 February 2020 / Accepted: 19 February 2020 / Published online: 3 March 2020

(c) The Author(s) 2020

\begin{abstract}
Quantitative coronary angiography (QCA) remains to play an important role in clinical trials and post-marketing surveillance related to the safety and efficacy of new PCI devices. In this document, the current standard methodology of QCA is summarized. In addition, its history, recent development and future perspectives are also reviewed.
\end{abstract}

Keywords Quantitative coronary angiography · Coronary artery disease · Coronary artery stents · Expert consensus document

\section{Introduction}

Percutaneous coronary intervention (PCI) is the standard of treatment for ischemic heart disease. An accurate assessment of stenosis and the reference diameter is important; hence, evaluation of coronary angiography is essential for PCI. In clinical settings, quantitative coronary angiography (QCA) is typically used to assess coronary artery stenosis.

Nobuaki Suzuki and Taku Asano contributed equally to this manuscript.

Ken Kozuma

PXE00364@nifty.com

1 Department of Fourth Internal Medicine, Teikyo University Mizonokuchi Hospital, Kawasaki, Japan

2 Department of Cardiology, St. Luke's Hospital, Tokyo, Japan

3 Department of Cardiovascular Medicine, Kindai University Faculty of Medicine, Osaka-Sayama, Japan

4 Division of Cardiology, Mitsui Memorial Hospital, Tokyo, Japan

5 Division of Cardiology, Yokohama City University Medical Center, Yokohama, Japan

6 Department of Cardiology, Tokai University Hospital, Isehara, Japan

7 Division of Cardiology, Department of Medicine, Teikyo University School of Medicine, 2-11-1, Kaga, Itabashi-ku, Tokyo, Japan
The visual assessment of lumen diameter and stenosis is not objective. Therefore, QCA was developed for the objective evaluation of lumen diameter. Truly, a report of the European Society of Cardiology-European Association of Percutaneous Cardiovascular Interventions Task Force on the Evaluation of Coronary Stents in Europe supports the importance of independent QCA analysis as follows; "Offline quantitative coronary analysis in a centralized core laboratory with blinded outcome assessors in case of comparative studies is mandatory" [1,2]. Also, the US Food and Drug Administration addresses that the independent quantitative angiographic assessment is momentous [2,3]. Accordingly, the Academic Research Consortium-2 Consensus Document recommends the use of independent core laboratoryverified QCA analysis using the hierarchical approach when the trial protocols are not incorporate the mandatory use of fractional flow reserve (FFR), or any other functional assessment [2]. In short, the hierarchical approach of the definition with respect to clinically indicated repeat revascularization is following: (1) QCA [preferably three-dimensional (3D) QCA] diameter stenosis $>50 \%$ (based on the average of multiple views) with either recurrent symptoms or positive noninvasive functional test; (2) QCA (preferably 3D QCA) diameter stenosis $>70 \%$ (based on the average of multiple views) regardless of other criteria; (3) QCA diameter stenosis $>70 \%$ (based on the worst view) regardless of other criteria. Thus, QCA remains to play an important role in 
clinical trials and post-marketing surveillance related to the safety and efficacy of new PCI devices.

\section{History and future perspectives}

Selective coronary angiography was born in 1959 [4], and generally accepted as the gold standard for the assessment of coronary artery disease. The American Heart Association reporting system for grading coronary artery disease was established in 1975 to standardize the evaluation of coronary angiography [5]. Of note, the visual assessment of coronary angiography is not necessarily strictly objective and intra- and inter-observer variabilities have become a great concern. Zie et al. reported that all observers agree regarding the significance of stenosis (defined as $>50 \%$ narrowing of the luminal diameter) in the proximal or mid-left anterior descending coronary artery in only $65 \%$ of coronary angiograms. Moreover, there was disagreement by at least one observer concerning the significance of lesions noted in the main left coronary artery in $15 \%$ of angiograms [6]. In addition, the introduction of balloon angioplasty and advances in medical therapy for atherosclerosis, offering potential for plaque regression, also required an objective and reproducible approach to accurately describe the dimensions of coronary arteries. In 1971, Gensini et al. reported an electronic caliper system in which the arterial border and normal segment of the lesion were manually defined

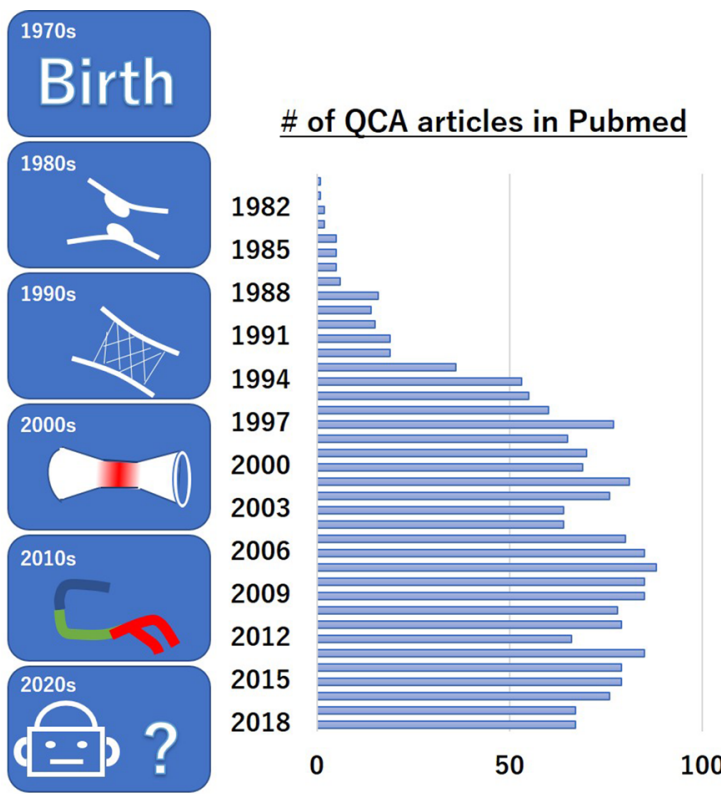

Fig. 1 History of quantitative coronary angiography. Quantitative coronary angiography (QCA) originated from the basic concept of showing objective numerical data in addition to a visual assessment. The emergence of metallic stents and drug-eluting stents has further increased its utility. As shown by the number of articles available in by moving the cursor [7]. The first validation study of QCA using digital computation was performed in 1977 [8]. In the 1980s, the Digital Imaging and Communications in Medicine (DICOM) system and novel contour detection algorithm [9] were developed to measure vessels with complex contour (e.g., post balloon dilatation, ruptured plaque), which are usually observed in daily clinical practice. Kondo et al. reported that it is reasonable to allow the edge-detection algorithm determine the measurements in types B and C dissected lesions in terms of predicting long-term patency after angioplasty [10]. These new technologies have contributed to the dramatic progress achieved in QCA.

In the 1990s, new devices [e.g., metallic stents, drugeluting stents (DES)] have been established to eliminate restenosis after PCI [11, 12]. QCA contributed greatly to the development of new devices and techniques by accurately measuring the late lumen loss and diameter of stenosis and judging those efficacies [13-33]. In the 2000s, it was established that evaluation of ischemia using FFR is useful for selecting appropriate lesions for PCI [34, 35]. Subsequently, 3D QCA, which was first conceived earlier [36], was applied to clinical practice. In the 2010s, the angiography-derived FFR method based on 3D QCA was introduced for a more accurate assessment of clinically significant stenosis [37]. $\mathrm{Tu}$ et al. showed that the angiography-derived FFR exhibits good correlation with FFR [38].

Figure 1 shows the quick history of QCA. Future developments in QCA in the 2020s remain unknown. QCA may

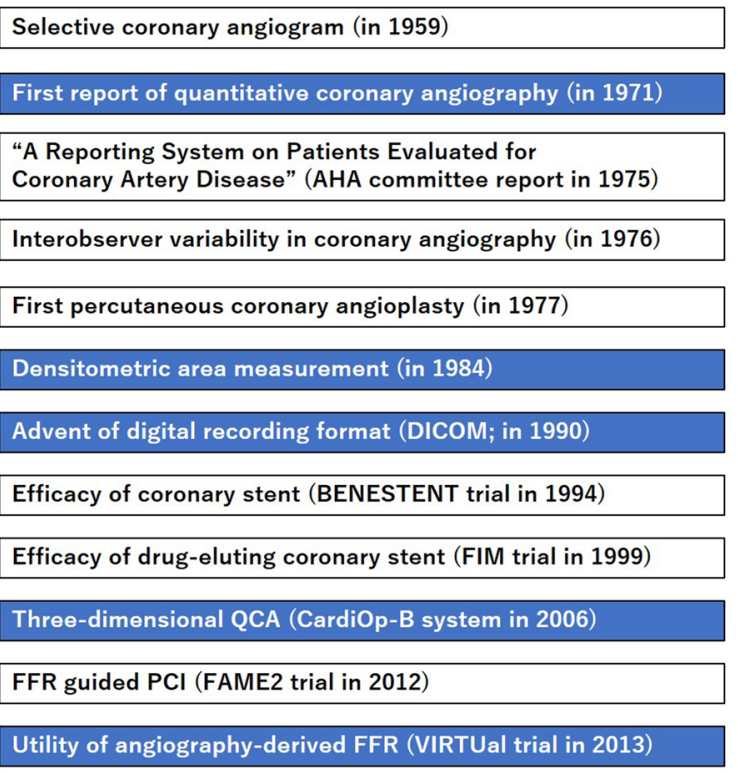

PubMed, even after the introduction of intravascular imaging and fractional flow reserve, QCA has maintained its value by applying three-dimensional QCA technology. FFR fractional flow reserve, $P C I$ percutaneous coronary intervention 
offer the potential for further development, through the application of artificial intelligence and the Internet, to improve the accuracy of decision-making in PCI. Advances in image enhancement continue to improve the usefulness of online quantification, while there is still room for development. Under the promotion of "Society 5.0" in Japan, online digital systems and computer application packages may become widely available in the future through commercial distribution. In combination with artificial intelligence, these systems may be designed to optimize the PCI procedure.

\section{Calibration}

Calibration is necessary to obtain measurement data through QCA analysis. Nowadays, progress in the isocenter technique method enables automatic image calibration by applying the data available in the DICOM file. Isocenter calibration transforms cardiac structures in digitized biplane angiograms into absolute dimensions, calculating their radiological magnification and video transformation [39]. Conventionally, this technique is based on two fixed reference points in the center of the two image intensifiers [40]. Application of flat panel and contemporary technologies ensured the accuracy of analysis through isocenter calibration, and led to the development of 3D QCA [41]. Accordingly, if the isocenter calibration is applicable, the catheter size does not need to be considered. Only when the isocenter calibration is applied, the size per pixel (calibration factor) in the cine must be evaluated using an object of predetermined size. These objects need to be visualized on the same picture with the target vessel. Calibration using a catheter was the most common approach in past era. Thus, it is necessary to capture images with a straightly positioned catheter in the Valsalva sinus. The recommended calibration factor for standard analysis software is $0.20 \pm 0.02 \mathrm{~mm} /$ pixel. In such situation, the analyst needs to enter the size of the catheter in the image into the program. The size of the catheter is preferably $\geq 6$ French. Indeed, Ito et al. reported that 4 French catheters are less reliable than 6 French catheters when measuring QCA data especially for follow-up data that need most accurate measurements of minimal lumen diameter and diameter stenosis [42]. Additional information regarding the catheter is not required, although a previous report showed the influence of the catheter type on the calibration [43].

\section{Analytical process and measurement data}

Initially, the edge of the contrasted blood vessel is drawn using an automatic edge-detection algorithm. Following the determination of a start point and an end point in the image of enhanced coronary artery, a vessel pathline is created. Subsequently, the vessel contour is delineated in accordance with the pathline. The pathline and vessel contour, which are determined automatically in accordance with the contrast density, occasionally requires editing by analysts. Lumen and reference diameters are displayed in the graph, which is helpful for editing. The automatically determined lesion length may also require review and editing by analysts. Especially at the post-PCI or follow-up phases, the border of the device must be manually pointed by the analysts, and the proximal and distal edge subsegments are subsequently determined. Generally, the following parameters are obtained through QCA: (1) minimal lumen diameter (the smallest diameter of the lumen); (2) reference diameter (the average diameter of the lumen assumed without atherosclerotic disease); (3) obstruction length (the QCA software automatically recognizes the two borders between the normal and diseased vessel by detecting the directional change in the coronary artery contour, and measures the length of stenosis). The following formulas provide the parameters enhancing the severity of obstruction and acute/ chronic outcome of interventional therapeutics: (1) diameter stenosis $=($ reference diameter - minimal lumen diameter)/reference diameter; (2) acute gain = post-PCI minimal lumen diameter - baseline minimal lumen diameter; (3) late loss $=$ post-PCI minimal lumen diameter - follow-up minimal lumen diameter. A more detailed report of some software also shows the mean lumen diameter.

A standard scheme is shown in Fig. 2. Following the emergence of brachytherapy and DES technologies, restenosis appeared at edge subsegment was more focused on $[44,45]$. In the current standard system using the DES analysis algorithm, a stent edge of $5 \mathrm{~mm}$ on both ends is automatically selected after the selection of the stent range. Conventionally, the analysis area was subjectively set by the analyst using the nearby side branches as landmarks. However, this algorithm automatically defines the analysis range of the stent and its surroundings, enabling more objective comparison.

Accurate measurement of the minimal lumen diameter and reference diameter leads to the accurate evaluation of late lumen loss and diameter of the stenosis, which are accepted by the medical community as efficacy endpoints. Late loss has been associated with long-term clinical events [46]. In fact, QCA made a great contribution in comparing the utility of each type of DES inhibiting neointimal hyperplasia in the early 2000s. Thus, contemporary clinical trials have shown the effectiveness of the new coronary device compared with that of devices of the previous generation based on the concept of late loss.

\section{Tips for obtaining optimal QCA data}

Operators must perform high-quality coronary angiography for accurate QCA. The images without guide wire need to be selected. Notably, use of an insufficient amount of contrast 

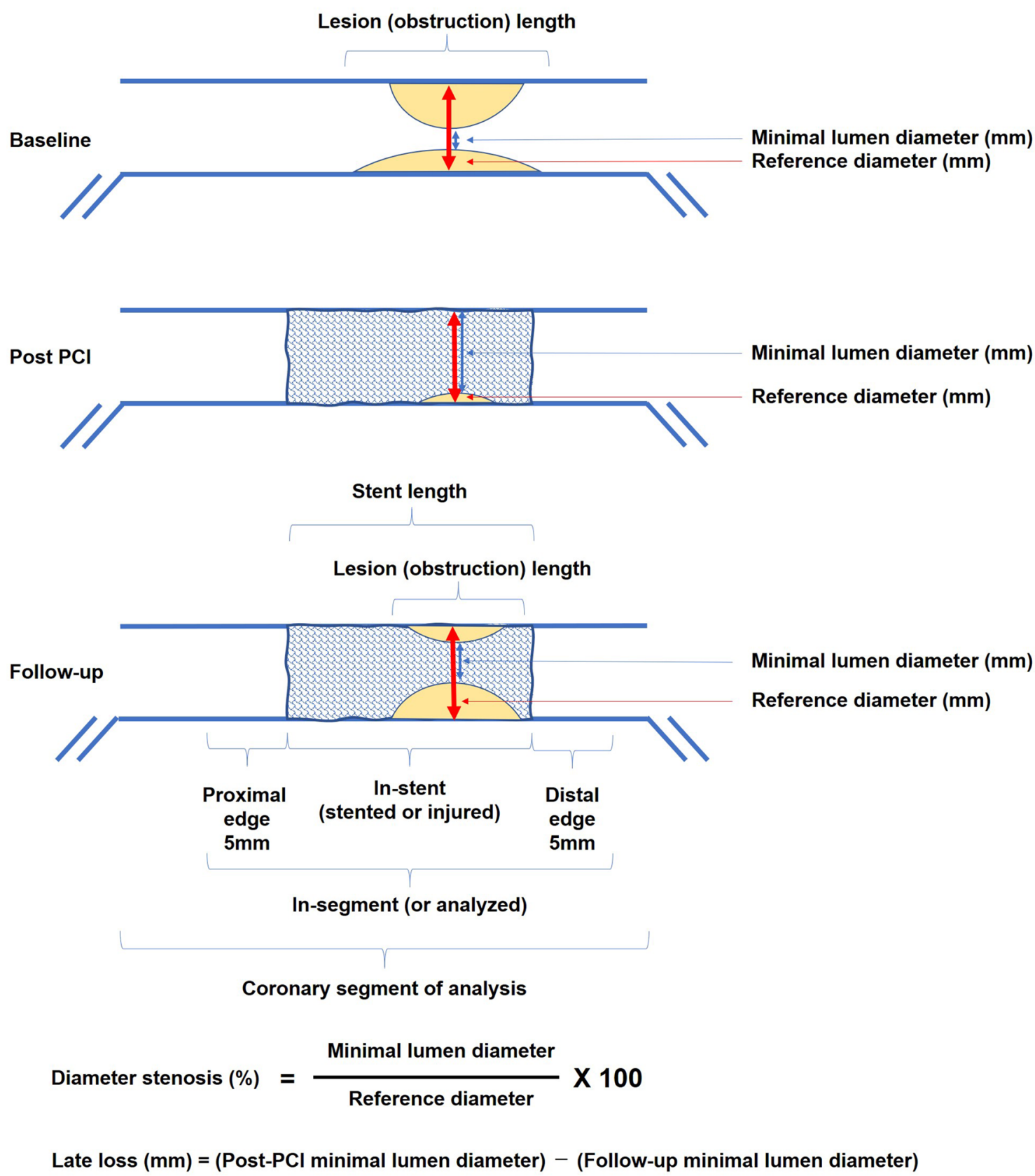

Fig. 2 Standard scheme of measurement data. $P C I$ percutaneous coronary intervention

medium usually results in incorrect determination of the vessel contour, which requires extensive editing. The setting of the auto injector may have to be altered in advance, especially for large vessels or patients with arteriovenous shunts undergoing hemodialysis. Crossing the side branch, which can result in an incorrect direction of the pathline, should be avoided. The angiographic conditions need to be consistent at the post-PCI and follow-up phases to accurately determine the late loss. Therefore, the operator must ensure the consistency of the oblique used for QCA in each phase.
In clinical practice, QCA data can be influenced by the frame selection [47]. In the selection of the target frame, the analyst should (1) minimize vessel movement, (2) select the contrast-filled vessels in the end-diastolic phase, and (3) appropriately include the calibration device when the isocenter calibration is not applicable.

One may think that differences in software programs influence the QCA measurements. However, Kozuma et al. reported that measurements of the minimal lumen diameter and reference diameter did not show major systematic 
differences between currently available software programs [48].

QCA measurements may not necessarily be consistent with those of other modalities. Kubo et al. reported that the measurement values in QCA are lower compared with those obtained through optical coherence tomography and intravascular ultrasound [49]. Furthermore, Sotomi et al. reported that the discrepancy between QCA and optical coherence tomography in terms of lumen loss was minor; however, it tended to be greater in the analysis of lesions with a bioresorbable scaffold [50].

Currently, there are several concerns regarding the interpretation of QCA measurements for diffuse lesions (Fig. 3). At baseline, the automated obstruction length and reference diameter are occasionally underestimated. Therefore, appropriate correction of the lesion length should be considered. Discrepancy may be observed in the diameter of stenosis at the follow-up phase and late loss. In case of a proximal restenosis after the stent implantation on diffuse lesion, the value of late lumen loss is usually unremarkable, whereas the diameter of stenosis is prominent. Concretely, the instent minimal lumen diameter is usually located distally at the post-PCI phase due to vessel tapering. However, when the restenosis appears far proximally, the value of late loss tends to be low despite binary restenosis. This discrepancy is so-called the previously reported "relocation" of the minimal lumen diameter [51]. Such discrepancy is usually more exaggerated in the measurement of the in-segment, when the minimal lumen diameter exhibits a markedly low value at the distal edge subsegment post-PCI.

Distal reference may not be necessarily included in the analysis of total occlusion. In such a case, the reference segment where the vessel size is supposed to be consistent with the occluded segment needs to be selected and only the reference diameter is to be measured. Subsequently, the diameter of the stenosis and minimal lumen diameter are manually determined as $100 \%$ and $0 \mathrm{~mm}$, respectively (Fig. 4).

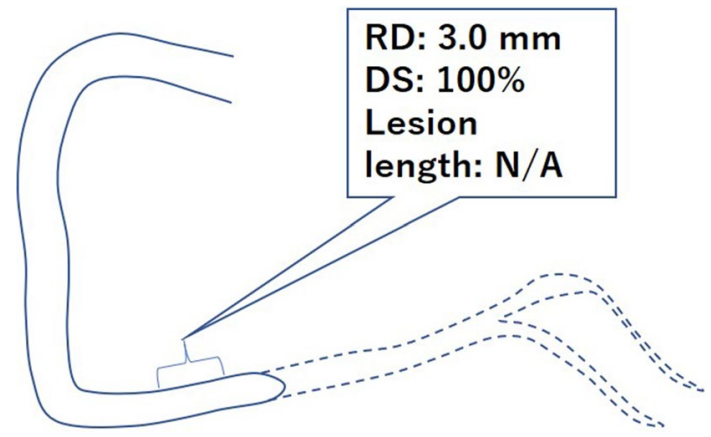

Fig. 4 An example of total occlusive lesion. $R D$ reference diameter, $D S$ diameter stenosis

\section{$\begin{array}{lll}\text { Baseline } & \text { Post } \mathrm{PCl} & \text { Follow-up }\end{array}$}

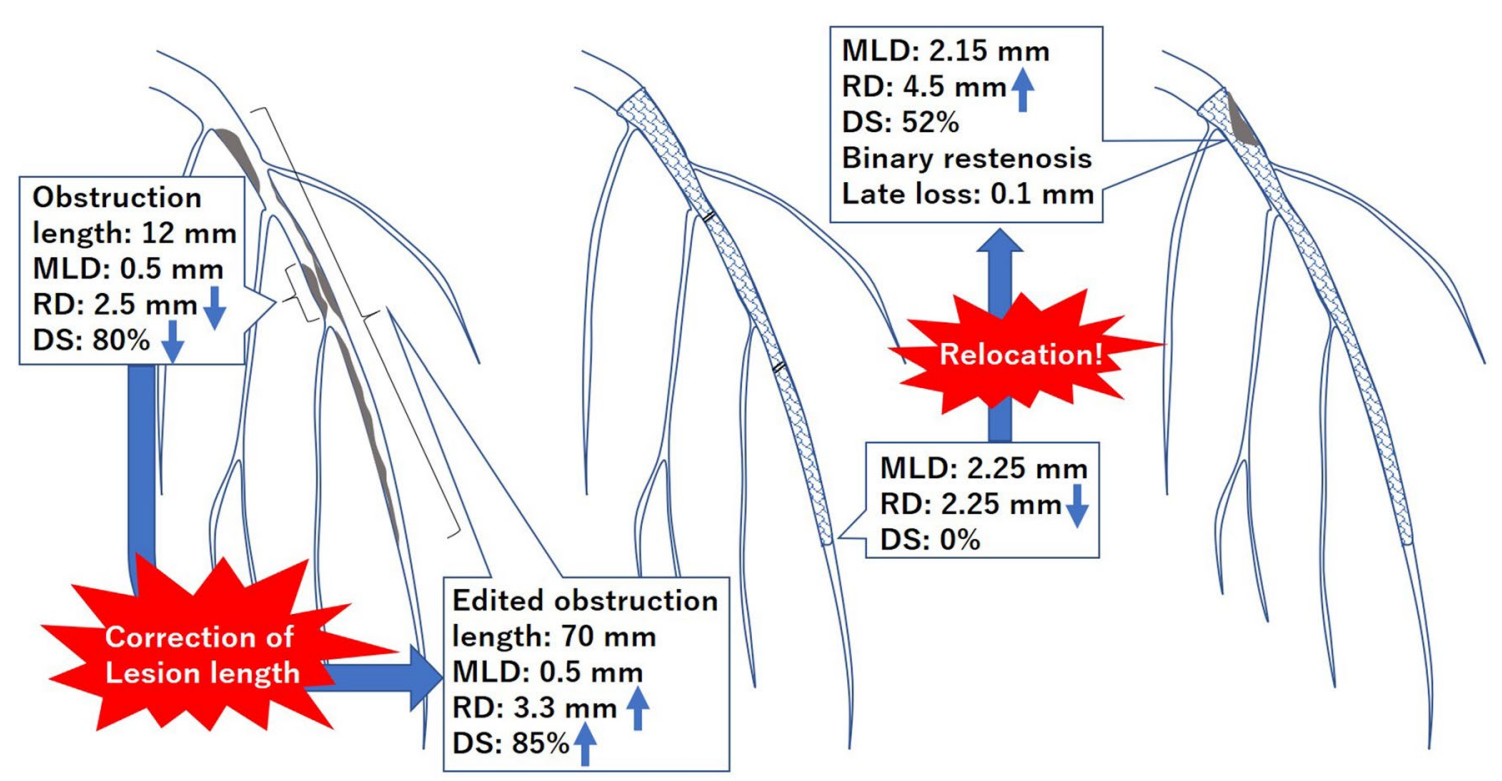

Fig. 3 A representative case of diffuse lesion. When the automated obstruction length and reference diameter are too underestimated at baseline, appropriate correction of the lesion length should be considered. When the in-stent restenosis appears proximally on diffuse lesion, the value of late lumen loss is usually unremarkable, whereas the diameter of stenosis is prominent. This discrepancy is so-called the previously reported "relocation" of the minimal lumen diameter. $M L D$ minimal lumen diameter, $R D$ reference diameter, $D S$ diameter stenosis 
The followings should be considered to optimize the results of QCA:

- To facilitate the frame selection, the frame rate should be $\geq 12.5 / \mathrm{s}$.

- The flat panel should be positioned to be the closest to patient.

- When the isocenter calibration is not applicable, the catheter size is preferably $\geq 6$ French.

- The setting of the auto-injector should be altered if the target vessel requires a large amount of contrast agent (e.g., large vessels, patients with arteriovenous shunts).

- Adequate oblique should be selected to avoid other branch crossing or foreshortening of the target lesion.

- In advance, actual stent length and diameter of devices should be reviewed.

- The position of the flat panel and oblique and any other conditions should be consistent between baseline, postPCI, and follow-up angiography. Inconsistency is occasionally responsible for unreasonable data.

\section{Bifurcation analysis}

The coronary tree is characterized by its natural fractal geometric pattern. In the coronary tree, whole upstream blood flow is distributed to downstream bifurcated branches. It is established that, in bifurcated vessel, the sizes of the daughter vessels (i.e., distal main branch and side branch) are smaller than that of the mother vessel (i.e., proximal main branch). Huo and Kassab et al. reported the relationship in diameter $(D)$ between the mother and daughter vessels as described below [52]:

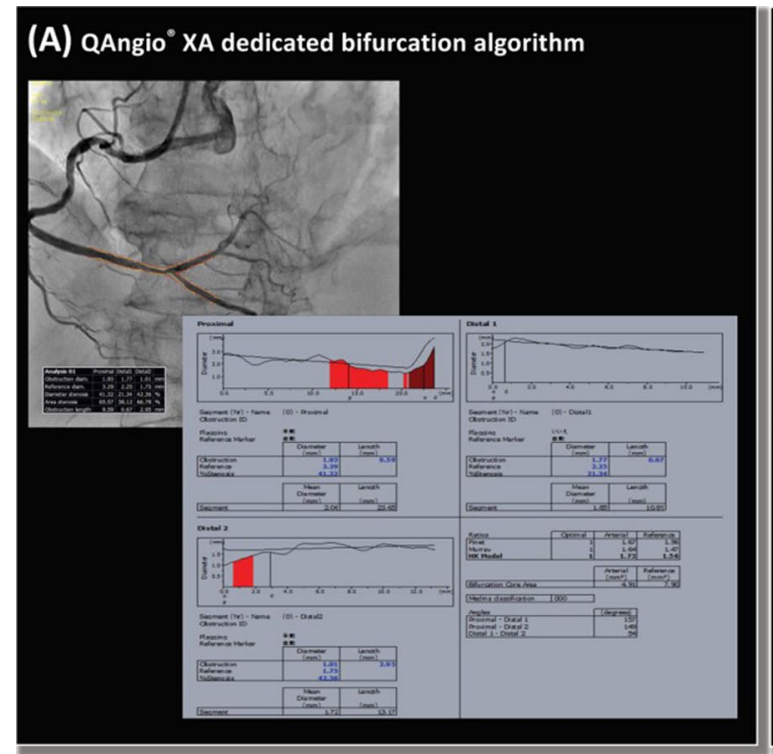

$D$ mother vessel ${ }^{\frac{7}{3}}=D$ larger daughter vessel ${ }^{\frac{7}{3}}$

$$
+D \text { smaller daughter vessel }{ }^{\frac{7}{3}} \text {. }
$$

According to this principle, the coronary artery changes its diameter at the point of bifurcation (step-down phenomenon). However, conventional single-vessel QCA algorithms were developed based on the assumption of minimum vessel tapering. It was reported that the accuracy of the singlevessel QCA algorithms in bifurcated lesion was limited [53]. Ishibashi et al. reported that the single-vessel QCA algorithms underestimated the diameter of stenosis in the proximal mother vessel due to underestimated interpolated reference vessel diameter and overestimated diameter stenosis in the distal daughter vessels due to overestimated reference vessel diameter [54]. Another limitation of the single-vessel QCA algorithms is the requirement of a non-existing vessel contour crossing a bifurcation core. This results in the need for manual corrections, potentially introducing bias [54].

Dedicated bifurcation QCA algorithms were developed to overcome these limitations. Major QCA software, such as QAngio ${ }^{\circledR}$ XA (Medis Medical Imaging systems B.V, Leiden, the Netherlands) and $\mathrm{CAAS}^{\circledR}$ (Pie Medical Imaging B.V, Maastricht, the Netherlands) optionally incorporate a two-dimensional (2D) bifurcation analysis package (Fig. 5). These dedicated bifurcation algorithms are based on a common concept that stenoses are individually assessed in each segment (i.e., proximal major branch, distal major branch, and side branch), with the segment-specified interpolated reference vessel diameter and vessel contours delineating actual bifurcation geometry avoiding the non-existing vessel contours across a bifurcation core. These algorithms have

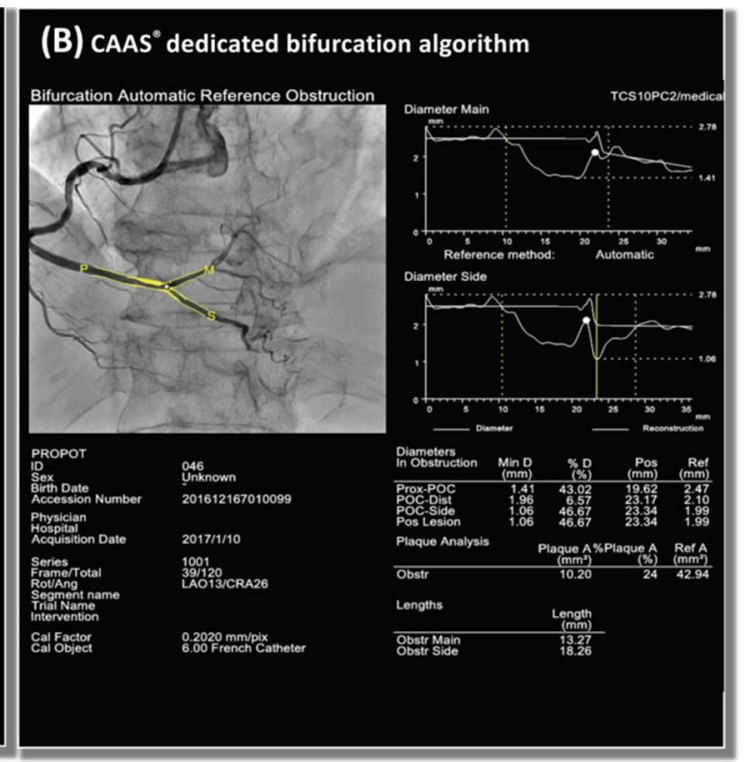

Fig. 5 Bifurcation analyses using bifurcation-dedicated algorithms on a QAngio ${ }^{\circledR}$ XA and $\mathbf{b} \mathrm{CAAS}^{\circledR}$ 
been validated using precision-manufactured bifurcation phantoms and compared with conventional single-vessel QCA algorithms [54]. In this validation study, the dedicated bifurcation algorithms yielded superior accuracy and precision than single-vessel QCA algorithms. Although the two different algorithms (i.e., QAngio ${ }^{\circledR}$ XA and CAAS ${ }^{\circledR}$ ) feature their original methodologies, they exhibited comparable analytic performance in the validation study [54].

For the appropriate quantitative angiographic assessment of bifurcated vessels, the consensus group recommends the following:

- The bifurcation should be assessed in the optimal angiographic view orthogonal to the bifurcation plane in which the widest bifurcation angle is visualized without overlapping or foreshortening of vessels.

- The dedicated bifurcation algorithm rather than the conventional single-vessel algorithm should be used, especially in the case of major bifurcation (e.g., left main coronary artery and major bifurcation in the proximal left anterior descending and left circumflex arteries).

- The quantitative and qualitative (i.e., calcification, thrombus dissection, etc.) results should be independently reported in each of three segments (i.e., proximal main branch, distal main branch, side branch), and the Medina classification (based on the quantitative analysis) should be reported [55]. For the additional report, detailed subsegments of each branch are defined using each of the

(A)
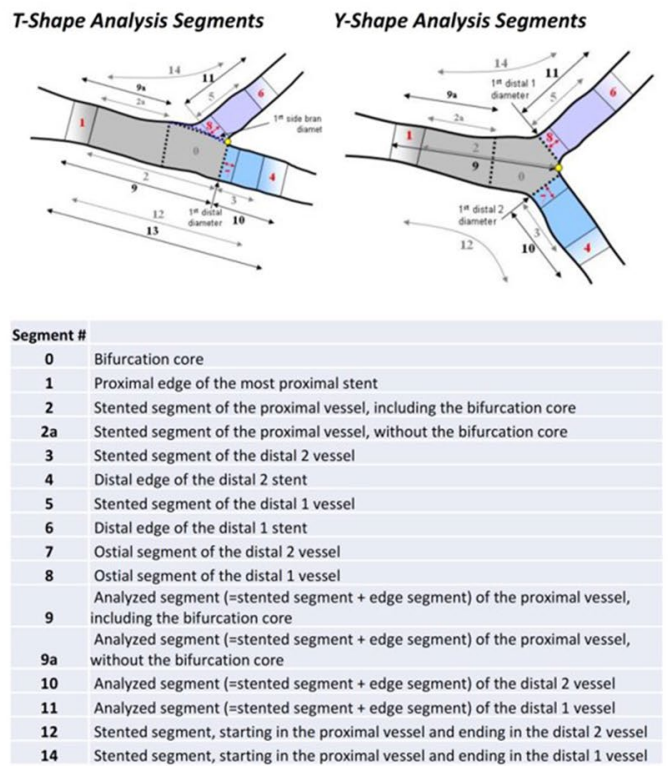

Fig. 6 Subsegments defined using bifurcation-dedicated algorithms on a QAngio ${ }^{\circledR} \mathrm{XA}$ and $\mathbf{b} \mathrm{CAAS}^{\circledR}$. a QAngio ${ }^{\circledR} \mathrm{XA}$ provides two different bifurcation analysis models (T-shape model and Y-shape software packages (14 subsegments on QAngio ${ }^{\circledR}$ XA and 6 or 11 subsegments on CAAS $^{\circledR}$ ) (Fig. 6).

- For the serial quantitative assessment of the efficacy of the intervention, the analyses should be performed at the time of pre-intervention, post-intervention, and follow-up with the same projection angle.

\section{Aorto-ostial analysis}

The QCA in aorto-ostial lesions requires several considerations. The ostial lesion should be assessed with the optimal viewing angle perpendicular to the ostium of the coronary artery. For the ostium of the left main coronary artery, AP, cranial $35^{\circ}-45^{\circ}$ and LAO $30^{\circ}-45^{\circ}$, cranial $25^{\circ}-35^{\circ}$ are options for the optimal view. [56] For the quantitative analysis, it is often difficult to define a proximal reference vessel due to an insufficient length of the healthy vessel proximal to the obstruction. This precludes researchers from defining an appropriately interpreted reference vessel diameter. When the automatic interpolated reference line is inappropriate, manual corrections of the reference line are needed. In the CAAS ${ }^{\circledR}$, the "local reference" function enables to modify the reference diameter by selecting a reference diameter location that the operator considers as a healthy diameter. In the QAngio ${ }^{\circledR} \mathrm{XA}$, the "flagging" function is used for the correction of the reference diameter. Furthermore, the QAngio ${ }^{\circledR}$ XA optionally incorporates the dedicated algorithm for ostial analysis. According to this algorithm, the reference

(B)
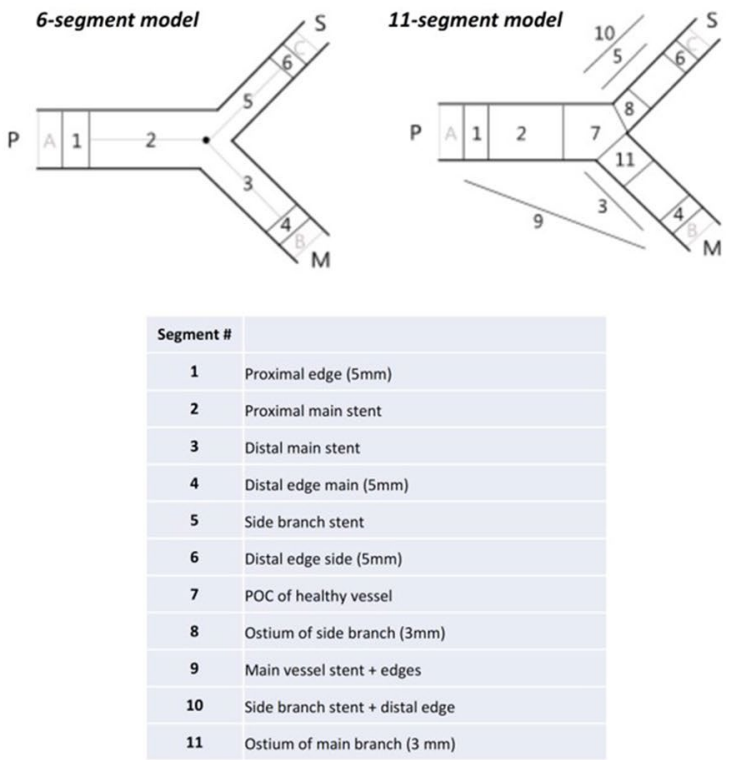

model) that are applied according to the morphology of the bifurcation. b CAAS ${ }^{\circledR}$ reports two different segment models (6- and 11-segment model). $P O C$ polygon of confluence 
diameter is interpolated based on the proximal segment with a limited length and distal reference segment.

\section{D quantitative coronary angiography}

The 3D QCA was developed to resolve several drawbacks of 2D QCA. In 3D QCA, at least two angiographic projections are required to reconstruct a 3D geometry $[57,58]$. The 3D geometry allows an accurate quantitative assessment of the eccentric cross-sectional luminal morphology of the coronary artery, which hinders precise analysis in 2D QCA. Furthermore, it averts inaccurate length measurement due to vessel shortening, which is frequently observed in 2D QCA. It was reported that the 3D QCA parameters more precisely reflected the luminal dimensions measured through intravascular ultrasound and FFR compared with 2D QCA [37, 59].

The advantage of 3D QCA is highlighted in the assessment of bifurcation. This is because the $3 \mathrm{D}$ reconstruction theoretically yields a precise geometric assessment, such as measurement of the bifurcation angle, which is commonly difficult in 2D QCA due to the overlap and foreshortening of branches. The superiority of the analytic performance of the $3 \mathrm{D}$ bifurcation algorithm over the $2 \mathrm{D}$ bifurcation algorithm in the assessment of bifurcation has been previously reported $[60,61]$. Furthermore, the 3D reconstruction aids the angiographer and interventionist to determine the optimal projection angle.

\section{Angiography-derived FFR}

In the 1980s and 1990s, the physiological assessment of coronary arteries was performed using "semi-quantitative" angiographic methodologies, such as Thrombolysis in Myocardial Infarction (TIMI) flow grade, TIMI frame count, and TIMI myocardial perfusion grade [62-64]. However, these methodologies are somewhat fuzzy, and thus have major limitations in providing accurate interpretation of the complex physiological phenomena [65, 66]. In 1993, N. Pijls and B. Bruyne invented FFR to assess the severity of physiological stenosis using a pressure wire $[67,68]$. This index was widely accepted for its feasibility with objective values, low dependence on the skills of the operator, and robust relationship with clinical prognosis $[69,70]$. Furthermore, other feasible and accurate wire-based indices using coronary thermodilution (i.e., coronary flow reserve and intracoronary microvascular resistance) were invented in the 2000s. These indices assisted in overcoming the limitations of the classic invasive coronary flow assessment with a Doppler wire. Subsequently, these novel wire-based indices replaced the classic angiographic physiological methodologies.

Following the advent of FFR, researchers attempted its computation based only on angiographic information (i.e., angiography-derived FFR). The initial angiography-derived FFR was developed based on the computer fluid dynamics with a complex mathematical formula (i.e., Navier-Stokes equation) which prolonged the calculation time to several days [71]. To overcome this limitation, Papafaklis et al. and Tu et al. reported the angiography-derived physiological indices with a simple mathematical formula based on Poiseuille's and Bernoulli's laws [38, 72]. These computed physiological indices, which could be acquired within 5-10 min, exhibited a satisfactory diagnostic performance in the validation studies, with the wire-based FFR used as Refs. [38, 72]. In the meta-analysis including angiography-derived FFR with various methodologies, the pooled sensitivity, specificity, and summarized area under the receiver-operating curve against the wire-based FFR were $0.89,0.90$, and 0.84 , respectively [73]. In the meta-analysis, the angiography-derived FFR based on the simple equation demonstrated a comparable diagnostic performance with that of angiography-derived FFR based on the Navier-Stokes equation.

Commercially available software packages for the angiography-derived FFR have been developed by Medis Medical Imaging System B.V. $\left(\mathrm{QFR}^{\circledR}\right.$ : Quantitative Flow Ratio), Pie Medical Imaging B.V. (vFFR ${ }^{\circledR}$ ), and CathWorks $\left(\right.$ FFRangio ${ }^{\circledR}$ ) (Fig. 7). These software packages provide an online analysis system enabling the acquisition of a computed FFR value in the Cath lab. They are expected to support physicians or operators in decision-making for the indication of revascularization without using a pressure wire. Considering the advantages of less invasiveness and timeeffectiveness, angiography-derived FFR potentially plays a role in specific situations, such as a non-culprit lesion assessment in the setting of acute coronary syndrome, post-PCI lesion assessment, and patient risk assessment using the functional SYNTAX score [74-78].

For a surrogate marker of stent efficacy, the potential applicability of the angiography-derived FFR as a new-generation QCA was reported [79]. A patient-level meta-analysis reported that even a statistically significant difference in angiographic late lumen loss within the low value range did not have a clinical impact [80]. Taking into account the nonlinear relationship between luminal loss and deterioration of coronary flow, it may be worth incorporating a physiological assessment (e.g., angiography-derived FFR) into the quantitative assessment of efficacy in the current DES era [81].

Another advantage of angiography-derived FFR is that it can be also analyzed in a post hoc manner. Based on this advantage, angiography-derived FFR is a one of the recommended tools in the second version of the Academic Research Consortium consensus document on clinical endpoints in coronary intervention trials for the confirmation of "clinically-indicated" or "ischemia-driven" repeat revascularization in the adjudication of clinical events [2]. 


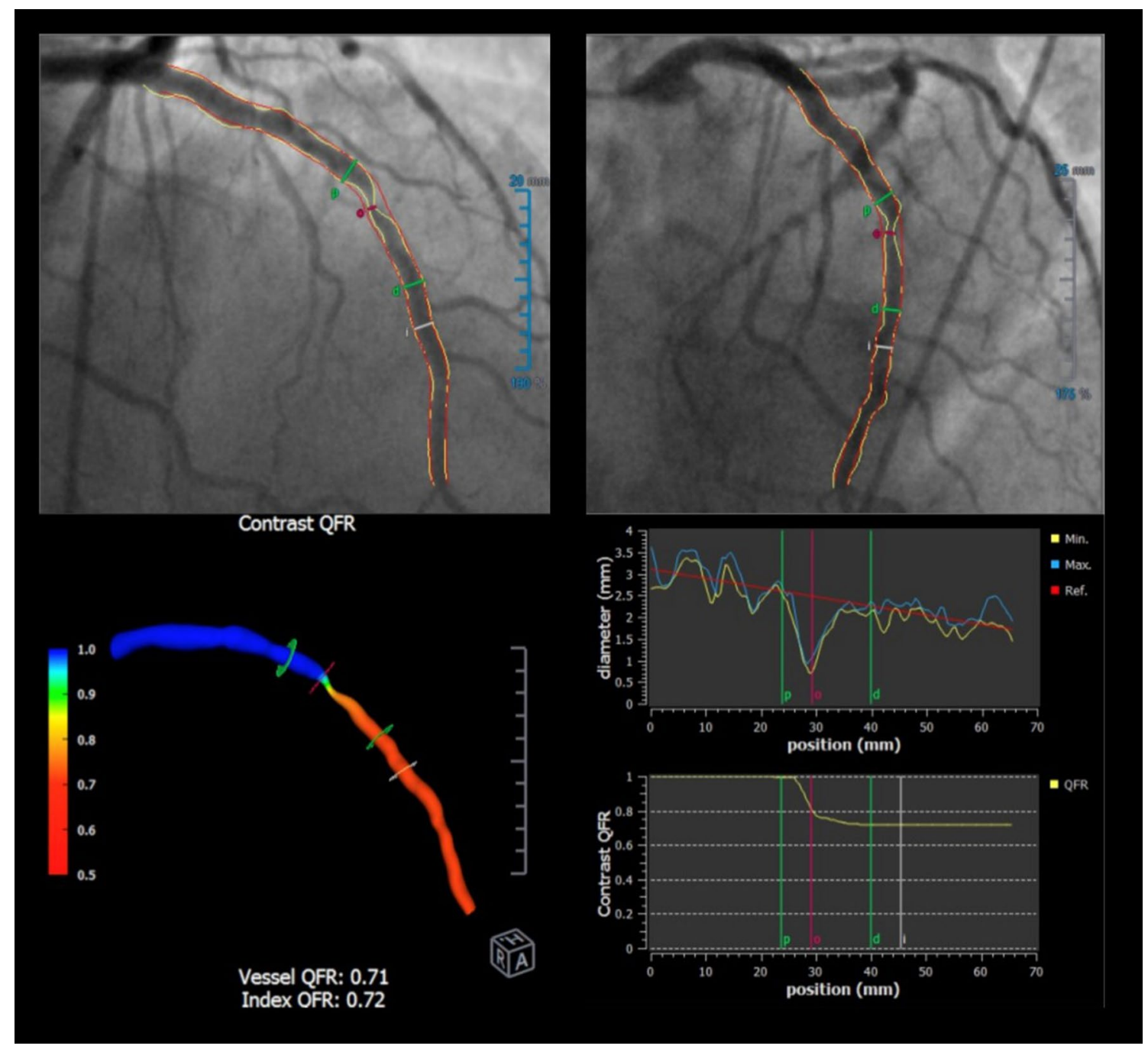

Fig.7 Quantitative flow ratio on QAngio ${ }^{\circledR}$ XA. The quantitative flow ratio (QFR) is computed based on three-dimensional angiography reconstructed from two different projections with angles $\geq 25^{\circ}$ apart and volumetric flow rate calculated using a contrast bolus frame count. The QFR reports virtual color-coded pullbacks of FFR of the arteries with stenosis for which angiography were performed, without the use of a pressure wire or hyperemia

\section{Funding None.}

\section{Compliance with ethical standards}

Conflict of interest All authors have reported that they have no relationships relevant to the contents of this paper to disclose.

Open Access This article is licensed under a Creative Commons Attribution 4.0 International License, which permits use, sharing, adaptation, distribution and reproduction in any medium or format, as long as you give appropriate credit to the original author(s) and the source, provide a link to the Creative Commons licence, and indicate if changes were made. The images or other third party material in this article are included in the article's Creative Commons licence, unless indicated otherwise in a credit line to the material. If material is not included in the article's Creative Commons licence and your intended use is not permitted by statutory regulation or exceeds the permitted use, you will need to obtain permission directly from the copyright holder. To view a copy of this licence, visit http://creativecommons.org/licenses/by/4.0/.

\section{References}

1. Byrne RA, Serruys PW, Baumbach A, Escaned J, Fajadet J, James S, et al. Report of a European Society of CardiologyEuropean Association of Percutaneous Cardiovascular Interventions task force on the evaluation of coronary stents in Europe: executive summary. Eur Heart J. 2015;36:2608-20.

2. Garcia-Garcia HM, McFadden EP, Farb A, Mehran R, Stone GW, Spertus J, et al. Standardized end point definitions for coronary intervention trials: the Academic Research Consortium-2 Consensus Document. Circulation. 2018;137:2635-50. 
3. Farb A, Zuckerman BD. Clinical event adjudication in cardiovascular device trials: an Food and Drug Administration perspective. Am Heart J. 2017;191:62-4.

4. West JW, Guzman SV. Coronary dilatation and constriction visualized by selective arteriography. Circ Res. 1959;7:527-36.

5. Austen WG, Edwards JE, Frye RL, Gensini GG, Gott VL, Griffith LS, et al. A reporting system on patients evaluated for coronary artery disease. Report of the Ad Hoc Committee for Grading of Coronary Artery Disease, Council on Cardiovascular Surgery, American Heart Association. Circulation. 1975;51:5-40.

6. Zir LM, Miller SW, Dinsmore RE, Gilbert JP, Harthorne JW. Interobserver variability in coronary angiography. Circulation. 1976;53:627-32.

7. Gensini GG, Kelly AE, Da Costa BC, Huntington PP. Quantitative angiography: the measurement of coronary vasomobility in the intact animal and man. Chest. 1971;60:522-30.

8. Brown BG, Bolson E, Frimer M, Dodge HT. Quantitative coronary arteriography: estimation of dimensions, hemodynamic resistance, and atheroma mass of coronary artery lesions using the arteriogram and digital computation. Circulation. 1977;55:329-37.

9. Serruys PW, Reiber JH, Wijns W, van den Brand M, Kooijman CJ, ten Katen HJ, et al. Assessment of percutaneous transluminal coronary angioplasty by quantitative coronary angiography: diameter versus densitometric area measurements. Am J Cardiol. 1984;54:482-8.

10. Kondo H, Ito S, Shigeyama J, Ito O, Matsushita T, Okamoto M, et al. Beneficial application of quantitative coronary angiography (edge detection algorithm) in analysis of dissected coronary arteries to predict long-term patency. Jpn Circ J. 2000;64:667-71.

11. Serruys PW, de Jaegere P, Kiemeneij F, Macaya C, Rutsch W, Heyndrickx G, et al. A comparison of balloon-expandablestent implantation with balloon angioplasty in patients with coronary artery disease. Benestent Study Group. N Engl J Med. 1994;331:489-95.

12. Sousa JE, Costa MA, Abizaid AC, Rensing BJ, Abizaid AS, Tanajura LF, et al. Sustained suppression of neointimal proliferation by sirolimus-eluting stents: 1-year angiographic and intravascular ultrasound follow-up. Circulation. 2001;104:2007-11.

13. Kimura T, Yokoi H, Nakagawa Y, Tamura T, Kaburagi S, Sawada $\mathrm{Y}$, et al. Three-year follow-up after implantation of metallic coronary-artery stents. N Engl J Med. 1996;334:561-6.

14. Tsuchikane E, Fukuhara A, Kobayashi T, Kirino M, Yamasaki K, Izumi M, et al. Impact of cilostazol on restenosis after percutaneous coronary balloon angioplasty. Circulation. 1999;100:21-6.

15. Tsuchikane E, Sumitsuji S, Awata N, Nakamura T, Kobayashi $\mathrm{T}$, Izumi M, et al. Final results of the STent versus directional coronary Atherectomy Randomized Trial (START). J Am Coll Cardiol. 1999;34:1050-7.

16. Suzuki T, Hosokawa H, Katoh O, Fujita T, Ueno K, Takase S, et al. Effects of adjunctive balloon angioplasty after intravascular ultrasound-guided optimal directional coronary atherectomy: the result of Adjunctive Balloon Angioplasty After Coronary Atherectomy Study (ABACAS). J Am Coll Cardiol. 1999;34:1028-35.

17. Kozuma K, Hara K, Yamasaki M, Morino Y, Ayabe S, Kuroda Y, et al. Effects of cilostazol on late lumen loss and repeat revascularization after Palmaz-Schatz coronary stent implantation. Am Heart J. 2001;141:124-30.

18. Nasu K, Tsuchikane E, Awata N, Matsumoto H, Shiota A, Takeda Y, et al. Quantitative angiographic and intravascular ultrasound study $>5$ years after directional coronary atherectomy. Am J Cardiol. 2004;93:543-8.

19. Ikari Y, Sakurada M, Kozuma K, Kawano S, Katsuki T, Kimura $\mathrm{K}$, et al. Upfront thrombus aspiration in primary coronary intervention for patients with ST-segment elevation acute myocardial infarction: report of the VAMPIRE (VAcuuM asPIration thrombus REmoval) trial. JACC Cardiovasc Interv. 2008;1:424-31.

20. Tsuchikane E, Suzuki T, Asakura Y, Oda H, Ueda K, Tanaka T, et al. Debulking of chronic coronary total occlusions with rotational or directional atherectomy before stenting: final results of DOCTORS study. Int J Cardiol. 2008;125:397-403.

21. Kimura T, Morimoto T, Natsuaki M, Shiomi H, Igarashi K, Kadota $\mathrm{K}$, et al. Comparison of everolimus-eluting and sirolimuseluting coronary stents: 1-year outcomes from the randomized evaluation of sirolimus-eluting versus everolimus-eluting stent trial (RESET). Circulation. 2012;126:1225-36.

22. Habara S, Iwabuchi M, Inoue N, Nakamura S, Asano R, Nanto $\mathrm{S}$, et al. A multicenter randomized comparison of paclitaxelcoated balloon catheter with conventional balloon angioplasty in patients with bare-metal stent restenosis and drug-eluting stent restenosis. Am Heart J. 2013;166:527-33.

23. Natsuaki M, Kozuma K, Morimoto T, Kadota K, Muramatsu $\mathrm{T}$, Nakagawa $\mathrm{Y}$, et al. Biodegradable polymer biolimus-eluting stent versus durable polymer everolimus-eluting stent: a randomized, controlled, noninferiority trial. J Am Coll Cardiol. 2013;62:181-90.

24. Natsuaki M, Kozuma K, Morimoto T, Shiomi H, Kimura T. Two-year outcome of a randomized trial comparing secondgeneration drug-eluting stents using biodegradable or durable polymer. JAMA. 2014;311:2125-7.

25. Kimura T, Kozuma K, Tanabe K, Nakamura S, Yamane M, Muramatsu T, et al. A randomized trial evaluating everolimuseluting absorb bioresorbable scaffolds vs. everolimus-eluting metallic stents in patients with coronary artery disease: ABSORB Japan. Eur Heart J. 2015;36:3332-42.

26. Ikari Y, Kyono H, Isshiki T, Ishizuka S, Nasu K, Sano K, et al. Usefulness of everolimus-eluting coronary stent implantation in patients on maintenance hemodialysis. Am J Cardiol. 2015;116:872-6.

27. Morino Y, Tobaru T, Yasuda S, Kataoka K, Tanabe K, Hirohata A, et al. Biodegradable polymer-based, argatroban-eluting, cobalt-chromium stent (JF-04) for treatment of native coronary lesions: final results of the first-in-man study and lessons learned. Eurointervention. 2016;12:1271-8.

28. Suzuki K, Ishikawa T, Mutoh M, Sakamoto H, Kubota T, Ogawa $\mathrm{T}$, et al. Midterm angiographic outcomes with sirolimus- and everolimus-eluting stents for small vessels in diabetic patients: propensity-score-matched comparisons in three different vessel diameters. Cardiovasc Interv Ther. 2018;33:205-16.

29. Saito S, Krucoff MW, Nakamura S, Mehran R, Maehara A, AlKhalidi HR, et al. Japan-United States of America Harmonized Assessment by Randomized Multicentre Study of OrbusNEich's Combo StEnt (Japan-USA HARMONEE) study: primary results of the pivotal registration study of combined endothelial progenitor cell capture and drug-eluting stent in patients with ischaemic coronary disease and non-ST-elevation acute coronary syndrome. Eur Heart J. 2018;39:2460-8.

30. Saito S, Ando K, Ito Y, Tobaru T, Yajima J, Kimura T, et al. Two-year results after coronary stenting of small vessels in Japanese population using 2.25-mm diameter sirolimus-eluting stent with bioresorbable polymer: primary and long-term outcomes of CENTURY JSV study. Cardiovasc Interv Ther. 2019;34:25-33.

31. Aoki J, Nakazawa G, Ando K, Nakamura S, Tobaru T, Sakurada $\mathrm{M}$, et al. Effect of combination of non-slip element balloon and drug-coating balloon for in-stent restenosis lesions (ELEGANT study). J Cardiol. 2019;74:436-42.

32. Onishi T, Onishi Y, Kobayashi I, Umezawa S, Niwa A. Drugcoated balloon angioplasty for de novo small vessel disease including chronic total occlusion and bifurcation in real-world clinical practice. Cardiovasc Interv Ther. 2019;34:139-48. 
33. Nagai T, Mizobuchi M, Funatsu A, Kobayashi T, Nakamura S. Acute and mid-term outcomes of drug-coated balloon following rotational atherectomy. Cardiovasc Interv Ther. 2019. https:// doi.org/10.1007/s12928-019-00611-y.

34. Matsuo H, Kawase Y. FFR and iFR guided percutaneous coronary intervention. Cardiovasc Interv Ther. 2016;31:183-95.

35. Kawase Y, Matsuo H, Akasaka T, Shiono Y, Tanaka N, Amano $\mathrm{T}$, et al. Clinical use of physiological lesion assessment using pressure guidewires: an expert consensus document of the Japanese Association of Cardiovascular Intervention and Therapeutics. Cardiovasc Interv Ther. 2019;34:85-96.

36. Saito T, Misaki M, Shirato K, Takishima T. Three-dimensional quantitative coronary angiography. IEEE Trans Biomed Eng. 1990;37:768-77.

37. Nishi T, Kitahara H, Fujimoto Y, Nakayama T, Sugimoto K, Takahara M, et al. Comparison of 3-dimensional and 2-dimensional quantitative coronary angiography and intravascular ultrasound for functional assessment of coronary lesions. J Cardiol. 2017;69:280-6.

38. Tu S, Westra J, Yang J, von Birgelen C, Ferrara A, Pellicano M, et al. Diagnostic accuracy of fast computational approaches to derive fractional flow reserve from diagnostic coronary angiography: the International Multicenter FAVOR Pilot Study. JACC Cardiovasc Interv. 2016;9:2024-35.

39. Wunderlich W, Fischer F, Linderer T, Kirkeeide RL. Analytic isocenter calibration. A new approach for accurate X-ray gantries. Angiology. 1995;46:577-82.

40. Hess OM, Buchi M, Kirkeeide RL, Muser M, Osenberg H, Niederer $\mathrm{P}$, et al. Quantitative coronary arteriography at rest and during exercise. In: Reiber JHC, Serruys PW, editors. Quantitative coronary arteriography. Dordrecht: Springer; 1991. p. 145-53.

41. Tomkowiak MT, Speidel MA, Raval AN, Van Lysel MS. Calibration-free device sizing using an inverse geometry X-ray system. Med Phys. 2011;38:283-93.

42. Ito S, Kinoshita K, Endo A, Nakamura M, Muramatsu T. Impact of catheter size on reliability of quantitative coronary angiographic measurements (comparison of $4 \mathrm{Fr}$ and $6 \mathrm{Fr}$ catheters). Heart Vessels. 2016;31:1752-7.

43. Tadehara F, Imazu M, Kono S, Sano K. Calibration with currently available low-radiopacity catheters for scaling in digital quantitative coronary angiography. Investig Radiol. 2001;36:705-12.

44. Sabate M, Costa MA, Kozuma K, Kay IP, van der Giessen WJ, Coen VL, et al. Geographic miss: a cause of treatment failure in radio-oncology applied to intracoronary radiation therapy. Circulation. 2000;101:2467-71.

45. Moses JW, Leon MB, Popma JJ, Fitzgerald PJ, Holmes DR, O'Shaughnessy C, et al. Sirolimus-eluting stents versus standard stents in patients with stenosis in a native coronary artery. N Engl J Med. 2003;349:1315-23.

46. Pocock SJ, Lansky AJ, Mehran R, Popma JJ, Fahy MP, Na Y, et al. Angiographic surrogate end points in drug-eluting stent trials: a systematic evaluation based on individual patient data from 11 randomized, controlled trials. J Am Coll Cardiol. 2008;51:23-32.

47. Ito S, Kinoshita K, Endo A, Nakamura M. Impact of cine frame selection on quantitative coronary angiography results. Clin Med Insights Cardiol. 2019;13:1179546819838232.

48. Kozuma K, Kashiwabara K, Shinozaki T, Oba K, Matsuyama Y. Two-by-two cross-over study to evaluate agreement between versions of a quantitative coronary analysis system (QAngio XA). Int J Cardiovasc Imaging. 2017;33:779-87.

49. Kubo T, Akasaka T, Shite J, Suzuki T, Uemura S, Yu B, et al. OCT compared with IVUS in a coronary lesion assessment: the OPUSCLASS study. JACC Cardiovasc Imaging. 2013;6:1095-104.
50. Sotomi Y, Onuma Y, Miyazaki Y, Asano T, Katagiri Y, Tenekecioglu $\mathrm{E}$, et al. Is quantitative coronary angiography reliable in assessing the late lumen loss of the everolimus-eluting bioresorbable polylactide scaffold in comparison with the cobalt-chromium metallic stent? Eurointervention. 2017;13:e585-94.

51. Costa MA, Sabate M, Angiolillo DJ, Hu P, Jimenez-Quevedo P, Corros $\mathrm{C}$, et al. Relocation of minimal luminal diameter after bare metal and drug-eluting stent implantation: incidence and impact on angiographic late loss. Catheter Cardiovasc Interv. 2007;69:181-8.

52. Huo Y, Finet G, Lefevre T, Louvard Y, Moussa I, Kassab GS. Optimal diameter of diseased bifurcation segment: a practical rule for percutaneous coronary intervention. Eurointervention. 2012;7:1310-6.

53. Lansky A, Tuinenburg J, Costa M, Maeng M, Koning G, Popma J, et al. Quantitative angiographic methods for bifurcation lesions: a consensus statement from the European Bifurcation Group. Catheter Cardiovasc Interv. 2009;73:258-66.

54. Ishibashi Y, Grundeken MJ, Nakatani S, Iqbal J, Morel MA, Genereux $\mathrm{P}$, et al. In vitro validation and comparison of different software packages or algorithms for coronary bifurcation analysis using calibrated phantoms: implications for clinical practice and research of bifurcation stenting. Catheter Cardiovasc Interv. 2015;85:554-63.

55. Girasis C, Onuma Y, Schuurbiers JC, Morel MA, van Es GA, van Geuns RJ, et al. Validity and variability in visual assessment of stenosis severity in phantom bifurcation lesions: a survey in experts during the fifth meeting of the European Bifurcation Club. Catheter Cardiovasc Interv. 2012;79:361-8.

56. Di Mario C, Sutaria N. Coronary angiography in the angioplasty era: projections with a meaning. Heart. 2005;91:968-76.

57. Klein JL, Hoff JG, Peifer JW, Folks R, Cooke CD, King SB 3rd, et al. A quantitative evaluation of the three dimensional reconstruction of patients' coronary arteries. Int J Card Imaging. 1998; 14:75-87.

58. Dvir D, Marom H, Guetta V, Kornowski R. Three-dimensional coronary reconstruction from routine single-plane coronary angiograms: in vivo quantitative validation. Int J Cardiovasc Intervent. 2005;7:141-5.

59. Yong AS, Ng AC, Brieger D, Lowe HC, Ng MK, Kritharides L. Three-dimensional and two-dimensional quantitative coronary angiography, and their prediction of reduced fractional flow reserve. Eur Heart J. 2011;32:345-53.

60. Onuma Y, Girasis C, Aben JP, Sarno G, Piazza N, Lokkerbol $\mathrm{C}$, et al. A novel dedicated 3-dimensional quantitative coronary analysis methodology for bifurcation lesions. Eurointervention. 2011;7:629-35.

61. Girasis C, Schuurbiers JC, Muramatsu T, Aben JP, Onuma Y, Soekhradj S, et al. Advanced three-dimensional quantitative coronary angiographic assessment of bifurcation lesions: methodology and phantom validation. Eurointervention. 2013;8:1451-60.

62. Group TS. The Thrombolysis in Myocardial Infarction (TIMI) trial. Phase I findings. N Engl J Med. 1985;312:932-6.

63. Gibson CM, Cannon CP, Daley WL, Dodge JT Jr, Alexander B Jr, Marble SJ, et al. TIMI frame count: a quantitative method of assessing coronary artery flow. Circulation. 1996;93:879-88.

64. Gibson CM, Cannon CP, Murphy SA, Ryan KA, Mesley R, Marble SJ, et al. Relationship of TIMI myocardial perfusion grade to mortality after administration of thrombolytic drugs. Circulation. 2000;101:125-30.

65. Ross AM, Neuhaus KL, Ellis SG. Frequent lack of correspondence among core laboratories in assessing TIMI flow grade after reperfusion therapy. Circulation. 1995;92:I-345.

66. Tanedo JS, Kelly RF, Marquez M, Burns DE, Klein LW, Costanzo MR, et al. Assessing coronary blood flow dynamics with the TIMI frame count method: comparison with simultaneous 
intracoronary Doppler and ultrasound. Catheter Cardiovasc Interv. 2001;53:459-63.

67. Pijls NH, van Son JA, Kirkeeide RL, De Bruyne B, Gould KL. Experimental basis of determining maximum coronary, myocardial, and collateral blood flow by pressure measurements for assessing functional stenosis severity before and after percutaneous transluminal coronary angioplasty. Circulation. 1993;87:1354-67.

68. De Bruyne B, Baudhuin T, Melin JA, Pijls NH, Sys SU, Bol A, et al. Coronary flow reserve calculated from pressure measurements in humans. Validation with positron emission tomography. Circulation. 1994;89:1013-22.

69. Tonino PA, De Bruyne B, Pijls NH, Siebert U, Ikeno F, vant't Veer M, et al. Fractional flow reserve versus angiography for guiding percutaneous coronary intervention. N Engl J Med. 2009;360:213-24.

70. De Bruyne B, Pijls NH, Kalesan B, Barbato E, Tonino PA, Piroth $\mathrm{Z}$, et al. Fractional flow reserve-guided PCI versus medical therapy in stable coronary disease. N Engl J Med. 2012;367:991-1001.

71. Morris PD, Ryan D, Morton AC, Lycett R, Lawford PV, Hose DR, et al. Virtual fractional flow reserve from coronary angiography: modeling the significance of coronary lesions: results from the VIRTU-1 (VIRTUal Fractional Flow Reserve From Coronary Angiography) study. JACC Cardiovasc Interv. 2013;6:149-57.

72. Papafaklis MI, Muramatsu T, Ishibashi Y, Lakkas LS, Nakatani S, Bourantas CV, et al. Fast virtual functional assessment of intermediate coronary lesions using routine angiographic data and blood flow simulation in humans: comparison with pressure wire-fractional flow reserve. Eurointervention. 2014;10:574-83.

73. Collet C, Onuma Y, Sonck J, Asano T, Vandeloo B, Kornowski R, et al. Diagnostic performance of angiography-derived fractional flow reserve: a systematic review and Bayesian meta-analysis. Eur Heart J. 2018;39:3314-21.

74. Sejr-Hansen M, Westra J, Thim T, Christiansen EH, Eftekhari A, Kristensen SD, et al. Quantitative flow ratio for immediate assessment of nonculprit lesions in patients with ST-segment elevation myocardial infarction-An iSTEMI substudy. Catheter Cardiovasc Interv. 2019;94:686-92.
75. Kogame N, Takahashi K, Tomaniak M, Chichareon P, Modolo $\mathrm{R}$, Chang CC, et al. Clinical implication of quantitative flow ratio after percutaneous coronary intervention for 3-vessel disease. JACC Cardiovasc Interv. 2019;12:2064-75.

76. Asano T, Katagiri Y, Chang CC, Kogame N, Chichareon P, Takahashi K, et al. Angiography-derived fractional flow reserve in the SYNTAX II trial: feasibility, diagnostic performance of quantitative flow ratio, and clinical prognostic value of functional SYNTAX score derived from quantitative flow ratio in patients with 3-vessel disease. JACC Cardiovasc Interv. 2019;12:259-70.

77. Suzuki N, Nishide S, Kimura T, Aoyagi T, Kanamori K, Shiratori $\mathrm{Y}$, et al. Relationship of quantitative flow ratio after secondgeneration drug-eluting stent implantation to clinical outcomes. Heart Vessels. 2019. https://doi.org/10.1007/s00380-019-01545 -4 .

78. Hamaya R, Hoshino M, Kanno Y, Yamaguchi M, Ohya H, Sumino $\mathrm{Y}$, et al. Prognostic implication of three-vessel contrast-flow quantitative flow ratio in patients with stable coronary artery disease. Eurointervention. 2019;15:180-8.

79. Asano T, Katagiri Y, Collet C, Tenekecioglu E, Miyazaki Y, Sotomi Y, et al. Functional comparison between the BuMA Supreme biodegradable polymer sirolimus-eluting stent and a durable polymer zotarolimus-eluting coronary stent using quantitative flow ratio: PIONEER QFR substudy. Eurointervention. 2018;14:e570-9.

80. Asano T, Serruys PW, Collet C, Miyazaki Y, Takahashi K, Chichareon $\mathrm{P}$, et al. Angiographic late lumen loss revisited: impact on long-term target lesion revascularization. Eur Heart J. 2018;39:3381-9.

81. Gould KL, Lipscomb K, Hamilton GW. Physiologic basis for assessing critical coronary stenosis. Instantaneous flow response and regional distribution during coronary hyperemia as measures of coronary flow reserve. Am J Cardiol. 1974;33:87-94.

Publisher's Note Springer Nature remains neutral with regard to jurisdictional claims in published maps and institutional affiliations. 